Epidemology

\title{
Racial differences in breast cancer survival in the Detroit Metropolitan area
}

\author{
Michael S. Simon ${ }^{1,2}$, Mousumi Banerjee ${ }^{3}$, Heather Crossley-May ${ }^{2}$, Fawn D. Vigneau ${ }^{2}$, \\ Anne-Michelle Noone ${ }^{3}$, and Kendra Schwartz ${ }^{2,4}$ \\ ${ }^{1}$ Division of Hematology and Oncology, Karmanos Cancer Institute at Wayne State University, Detroit, MI, USA; \\ ${ }^{2}$ Population Studies and Prevention Program, Karmanos Cancer Institute at Wayne State University, Detroit, MI, \\ USA; ${ }^{3}$ Department of Biostatistics, School of Public Health, University of Michigan, Ann Arbor, MI, USA; \\ ${ }^{4}$ Department of Family Medicine, Wayne State University, Detroit, MI, USA
}

Key words: breast cancer, racial differences, survival

\begin{abstract}
Summary
African American (AA) women have poorer breast cancer survival compared to Caucasian American (CA) women. The purpose of this analysis was to determine whether socioeconomic status (SES) and treatment differences influence racial differences in breast cancer survival. The study population included 9,321 women (82\% CA, 18\% AA) diagnosed with local $(63 \%)$ or regional (37\%) stage disease between 1988 and 1992, identified through the Metropolitan Detroit SEER registry. Data on SES were obtained through linkage with the 1990 Census of Population and Housing Summary Tape and cases were geocoded to census block groups. Pathology, treatment and survival data were obtained through SEER. Cox proportional hazards models were used to compare survival for AA versus CA women after adjusting for age, SES, tumor size, number of involved lymph nodes, and treatment. AA women were more likely to live in a geographic area classified as working poor than were CA women $(p<0.001)$. AA women were less likely to have lumpectomy and radiation and more likely to have mastectomy with radiation $(p<0.001)$. After multivariable adjusted analysis, there were no significant racial differences in survival among women with local stage disease, although AA women with regional stage disease had persistent but attenuated poorer survival compared to CA women. After adjusting for known clinical and SES predictors of survival, AA and CA women who are diagnosed with local disease demonstrate similar overall and breast cancer-specific survival, while race continues to have an independent effect among women presenting at a later stage of disease.
\end{abstract}

\section{Introduction}

Although breast cancer $(\mathrm{BC})$ incidence rates are higher among Caucasian American (CA) women than African American (AA) women in the U.S. [1], mortality from breast cancer is higher among AA women [2]. A number of population-based studies using Surveillance Epidemiology and End Results (SEER) registry data [3-13] as well as studies of populations from hospitals and health care systems [14-19], have shown worse prognostic features and lower survival rates for $\mathrm{AA}$ and other ethnic minority women with BC compared with CA women. At least some of the reported racial differences in survival could be accounted for by either socioeconomic differences $[3,5,12,13,18-21]$ and or differences in access to medical care or poor quality care $[7-9,11,15,22]$. In a recently published analysis of AA and CA female breast cancer patients treated at a single large comprehensive cancer center in Detroit, no measurable racial differences in treatments were found, and multivariate adjusted analysis revealed no racial differences in disease free or overall survival [14]. The results of this latter study suggest that equal access to treatment results in equal outcomes.

We previously reported on racial differences in breast cancer survival in the Detroit Metropolitan area [3,22] showing a significant interaction between age at diagnosis and race. The current report updates our previous work by nearly doubling the period of follow-up, taking into account differences in cancer directed treatment and using a more refined measure of socioeconomic status (SES) [23]. We confined the current analysis to women diagnosed with either local or regional stage disease since in this and previous analyses [3] we found no racial differences in survival among women presenting with distant disease.

\section{Methods \\ Population for analysis}

The study population consisted of women diagnosed with a first primary invasive breast cancer (International 
Classification of Diseases for Oncology ICD-O codes C 50.0 to C 50.9) [24] from 1988 through 1992, identified through the population-based Metropolitan Detroit Cancer Surveillance System (MDCSS). The MDCSS is one of 7 founding members of the National Cancer Institute's Surveillance, Epidemiology, and End Results (SEER) program, which was initiated in 1973 [2]. For the current analysis we included women with either local or regional stage disease as defined by the SEER program. Localized stage includes invasive carcinoma confined to the breast. Regional stage includes invasive carcinoma spread beyond the breast, either by direct extension or to regional lymph nodes [25]. All women in the analysis were residents of the tri-county Detroit metropolitan area (Wayne, Oakland and Macomb counties) at the time of diagnosis. Women whose only documentation of $\mathrm{BC}$ was by death certificate were not included.

From 1988 to 1992 there were 10,314 incident cases of female invasive breast cancer diagnosed in the Detroit metropolitan area. We excluded 717 (6.95\%) women from our analysis with distant (metastatic) disease at diagnosis because survival was similarly poor for both racial groups in our preliminary analyses. There were an additional $276(2.67 \%)$ women excluded for whom tumor size could not be classified because there was either no mass identified, only microscopic tumor foci were noted, Paget's disease or inflammatory breast cancer were diagnosed. The population for analysis consisted of 9321 women: $7641(82.0 \%)$ were classified in the SEER registry as CA and $1680(18.0 \%)$ were classified as AA.

\section{Measurement of variables}

Medical and demographic data were obtained by the MDCSS on incident BC cases from all area facilities that provide medical care including hospitals, radiation therapy facilities, and private laboratories. Demographic data collected included age at diagnosis and race (AA or CA). Using address at diagnosis, the SES Group variable was developed through a geo-coding process that first assigned a census block-group number, as previously described [26]. Aggregate socioeconomic data specific to census block-groups were obtained from the 1990 U.S. Census of Population and Housing Summary Tape File 3A [27]. The variables and codes used to calculate the SES Group for each census block were occupation (P078), poverty status in 1989 (P119), educational attainment (P057), and age (P013).

The U.S. Census Bureau uses 13 occupational categories of which five are defined as "professional" occupations and the remaining 8 are identified as "working class" occupations. Working class blockgroups were defined as those areas in which $66 \%$ or more of employed persons in that particular blockgroup reported a working class occupation, such as administrative support or laborer. Professional blockgroups were defined as those areas where $34 \%$ or more of employed persons had supervisory or executive positions. Poor block-groups had $20 \%$ or more of the population below poverty level, defined as an income of $\$ 12,674$ for family of four in 1990 . Educational status was used to classify block-groups as either educated, in which $75 \%$ or more of persons age 25 years and older had completed at least a high school education, or undereducated block groups.

The SES Groups for this analysis were computed for each woman according to the method of Krieger et al. [28]. Women were initially assigned to one of eight SES Groups which included: (1) Working, Poor, Undereducated, (2) Working, Poor, Educated, (3) Working, Non-poor, Undereducated, (4) Working, Non-poor, Educated, (5) Professional, Poor, Undereducated, (6) Professional, Poor, Educated, (7) Professional, Nonpoor, Undereducated, and (8) Professional, Non-poor, Educated. Due to small numbers of cases in some groups, we collapsed cases into four mutually exclusive SES categories: (1) Working, Poor (WP); (2) Working, Non-poor, Undereducated (WNP-UE); (3) Working, Non-poor, Educated (WNP-E); and (4) Professional (P).

Clinical data included registry stage (as defined above), tumor size, number of involved axillary lymph nodes, histological grade, and hormone receptor status (estrogen receptor status (ER) and/or progesterone receptor (PR)). Information was collected on breast cancer directed therapy from the SEER "first course of treatment" variable. Treatment categories included lumpectomy or mastectomy with or without radiation therapy. Information on the administration of chemoor hormonal therapy was not included in this analysis because these treatments are often administered outside the facilities where SEER data are collected, and are thereby known to be incomplete.

Follow-up of all patients through June 2002 occurred by record linkage to hospital tumor registries, physician contacts, hospices, voting records, driver's license records, death certificates and review of obituaries [2]. Overall survival (measured in months) was calculated as the interval between date of diagnosis and date of last follow-up (censored observations) or death from any cause. We analyzed both overall survival and breast cancer specific survival. By the end of the study period, 3822 deaths had occurred, with 3001 deaths among CA women (39.3\% of all CA women) and 821 deaths among AA women ( $48.9 \%$ of all AA women). Breast cancer was listed on death certificate as the underlying cause of death for 1,812 of the women who had died. This included 1359 deaths from breast cancer among CA women $(17.8 \%$ of all CA women) and $453 \mathrm{BC}$ deaths among AA women (27\% of all AA women).

\section{Design and analysis}

Mantel-Haenszel chi-square statistics were used to compare the distributions of demographic and clinical characteristics in the two racial groups studied. (Table 1) [29]. Cox proportional hazards regression was used to estimate the hazard ratio (HR, 95\% CI) of death 
Table 1. Distribution of demographic and clinical characteristics by race among women with invasive breast cancer diagnosed in the Detroit Metropolitan area (1988-1992) ${ }^{\mathrm{a}}$

\begin{tabular}{|c|c|c|c|c|c|}
\hline \multirow[t]{2}{*}{ Characteristic } & \multicolumn{2}{|l|}{ AA } & \multicolumn{2}{|l|}{$\mathrm{CA}$} & \multirow[t]{2}{*}{$p$-value } \\
\hline & $n$ & $\%$ & $n$ & $\%$ & \\
\hline \multicolumn{6}{|l|}{ Age (years) } \\
\hline$\leq 50$ & 562 & 33.45 & 1821 & 23.84 & $<0.001$ \\
\hline$>50$ & 1118 & 66.55 & 5820 & 76.16 & \\
\hline \multicolumn{6}{|l|}{ SES group ${ }^{\mathrm{b}}$} \\
\hline WP & 1045 & 62.20 & 595 & 7.79 & $<0.001$ \\
\hline WNP-UE & 213 & 12.68 & 1827 & 23.91 & \\
\hline WNP-E & 99 & 5.89 & 1705 & 22.31 & \\
\hline $\mathrm{P}$ & 321 & 19.11 & 3510 & 45.94 & \\
\hline Missing & 2 & 0.12 & 4 & 0.05 & \\
\hline \multicolumn{6}{|l|}{ Tumor size } \\
\hline$\leq 2 \mathrm{~cm}$ & 718 & 42.74 & 4372 & 57.21 & $<0.001$ \\
\hline $2.1-5 \mathrm{~cm}$ & 664 & 39.52 & 2279 & 29.82 & \\
\hline $5.1-10 \mathrm{~cm}$ & 135 & 8.04 & 323 & 4.23 & \\
\hline$>10 \mathrm{~cm}$ & 16 & 0.95 & 29 & 0.38 & \\
\hline Missing & 147 & 8.75 & 638 & 8.36 & \\
\hline \multicolumn{6}{|l|}{ Lymph node involvement } \\
\hline 0 & 784 & 46.67 & 4281 & 56.02 & $<0.001$ \\
\hline $1-3$ & 349 & 20.77 & 1412 & 18.48 & \\
\hline 4-9 & 169 & 10.06 & 616 & 8.06 & \\
\hline$\geq 10$ & 83 & 4.94 & 347 & 4.54 & \\
\hline Missing & 295 & 17.56 & 985 & 12.90 & \\
\hline \multicolumn{6}{|l|}{ Treatment } \\
\hline Lumpectomy & 190 & 11.31 & 812 & 10.63 & $<0.001$ \\
\hline Lumpectomy + Radiation & 295 & 17.56 & 1660 & 21.72 & \\
\hline Mastectomy & 1030 & 61.31 & 4705 & 61.58 & \\
\hline Mastectomy + Radiation & 131 & 7.8 & 369 & 4.83 & \\
\hline Missing & 34 & 2.02 & 95 & 1.24 & \\
\hline \multicolumn{6}{|l|}{ Grade } \\
\hline Well Differentiated & 58 & 3.45 & 333 & 4.36 & $<0.001$ \\
\hline Moderately Differentiated & 267 & 15.89 & 1126 & 14.73 & \\
\hline Poorly Differentiated & 437 & 26.01 & 1231 & 16.11 & \\
\hline Undifferentiated & 42 & 2.5 & 113 & 1.48 & \\
\hline Missing & 876 & 52.14 & 4838 & 63.32 & \\
\hline \multicolumn{6}{|l|}{$E R$} \\
\hline Positive & 469 & 27.92 & 2710 & 35.46 & $<0.001$ \\
\hline Negative & 284 & 16.90 & 698 & 9.13 & \\
\hline Missing & 927 & 55.18 & 4233 & 55.4 & \\
\hline \multicolumn{6}{|l|}{$P R$} \\
\hline Positive & 413 & 24.58 & 2322 & 30.38 & $<0.001$ \\
\hline Negative & 339 & 20.18 & 1048 & 13.71 & \\
\hline Missing & 928 & 55.24 & 4271 & 55.90 & \\
\hline
\end{tabular}

${ }^{\mathrm{a}}$ Includes only women with localized and regional stage disease according to the SEER stage criteria.

${ }^{\mathrm{b}}$ WP-working poor; WNP-UE-working, non-poor, undereducated; WNP-E-working, non-poor, educated; P-professional.

from any cause, as well as breast cancer specific deaths, in AA women compared to CA women while controlling for appropriate covariates [30]. Survival analyses were stratified by SEER registry stage (local or regional stage) of disease. Independent variables used in the multivariable Cox model included race (AA vs. CA), age at diagnosis $(\leq 50$ vs. $>50$ ), SES group (WP, WNP-UE, WNP-E, P) tumor size ( $\leq 2 \mathrm{~cm}, 2.1-5 \mathrm{~cm},>5 \mathrm{~cm})$ lymph node involvement $(0,1-3,4-9, \geq 10)$ and cancer-directed treatment (lumpectomy, lumpectomy + radiation, mastectomy, mastectomy + radiation). Tumor grade and hormone receptor status were not included in the multivariable model because of the large proportion of missing data (over $50 \%$ ) for these variables. Potential interactions between race and other independent variables were assessed and the statistical significance of 
interaction terms was evaluated using likelihood ratio tests.

\section{Results}

Demographic and clinical characteristics of the study cohort stratified by race are listed in Table 1 . The mean age at diagnosis was 61 years (range 17-104) and the median period of follow-up was 97 months (maximum 154). There were statistically significant differences between AA and CA for all of the independent variables listed in the table. AA women were more likely than CA to be younger at diagnosis with $33 \%$ of AA women diagnosed at age 50 or younger compared to $24 \%$ of CA women $(p<0.001)$. AA women were more likely to reside in a census area that had a higher proportion of individuals categorized as WP and a lower proportion categorized as $\mathrm{P}$. At the time of diagnosis, $62 \%$ of AA women resided in a WP census block while only $19 \%$ of AA patients resided in $\mathrm{P}$ census block. In contrast, $8 \%$ of CA women resided in a WP block, and $46 \%$ resided in a P block $(p<0.001)$.

AA women were also more likely than CA women to have more advanced stage tumors at diagnosis. AA women were more likely to present with larger diameter tumors (almost twice as many AA vs. CA had tumors greater than $5 \mathrm{~cm}$ in greatest diameter, $p<0.001)$ and were also more likely to present with axillary lymph nodes that were involved with cancer $(36 \%$ of AA compared with $31 \%$ of CA, $p<0.001$ ). A greater proportion of AA women had poorly differentiated tumors $(26 \%$ vs. $16 \% p<0.001)$, and a greater proportion of tumors among AA women were either ER negative $(17 \%$ vs. $9 \% p<0.001)$ or PR negative $(20 \%$ vs. $14 \%$ $p<0.001)$.

In regards to treatment, AA women were more likely than CA women to have had a mastectomy $(69 \%$ vs. $66 \% p<0.001)$ and less likely to have had lumpectomy $(29 \%$ vs. $32 \% p<0.001)$ with the greatest percentage difference by race seen among women who received both lumpectomy and radiation therapy ( $18 \%$ for AA vs. $22 \%$ for CA $p<0.001)$.

The results of multivariable models of racial differences in overall survival are stratified by SEER registry stage (Table 2). Each model provides the unadjusted hazard ration (HR) for race and the adjusted HR controlling for age, SES group, tumor size, axillary lymph node involvement and treatment. By definition, whether or not axillary lymph nodes were involved was not applicable for patients with local stage disease. While the unadjusted HR $(95 \% \mathrm{CI})$ of death for AA compared

Table 2. Hazards of the risk of overall death among AA and CA women with local and regional disease

\begin{tabular}{|c|c|c|}
\hline Characteristic & Local $(n=5890)$ HR $(95 \%$ CI $)$ & Regional $(n=3431) \mathrm{HR}(95 \% \mathrm{CI})$ \\
\hline \multicolumn{3}{|l|}{ Unadjusted } \\
\hline Race (Black vs. White) & $1.28(1.15-1.44)$ & $1.45(1.30-1.61)$ \\
\hline \multicolumn{3}{|l|}{ Multivariable adjusted } \\
\hline Race (Black vs. White) & $1.07(0.90-1.27)$ & $1.27(1.10-1.46)$ \\
\hline \multicolumn{3}{|l|}{ Age (years) } \\
\hline$\leq 50$ & 1.00 & 1.00 \\
\hline$>50$ & $2.35(2.00-2.77)$ & $1.58(1.41-1.77)$ \\
\hline \multicolumn{3}{|l|}{ SES group ${ }^{\mathrm{a}}$} \\
\hline WP & $1.34(1.13-1.60)$ & $1.24(1.06-1.45)$ \\
\hline WNP-UE & $1.18(1.03-1.35)$ & $1.20(1.05-1.36)$ \\
\hline WNP-E & $0.99(0.85-1.15)$ & $1.02(0.88-1.17)$ \\
\hline $\mathrm{P}$ & 1.00 & 1.00 \\
\hline \multicolumn{3}{|l|}{ Tumor size } \\
\hline$\leq 2 \mathrm{~cm}$ & 1.00 & 1.00 \\
\hline $2.1-5 \mathrm{~cm}$ & $1.51(1.34-1.70)$ & $1.59(1.42-1.77)$ \\
\hline$>5 \mathrm{~cm}$ & $1.92(1.39-2.66)$ & $2.10(1.78-2.47)$ \\
\hline \multicolumn{3}{|l|}{ Lymph node involvement } \\
\hline 0 & & 1.00 \\
\hline $1-3$ & & $1.23(0.95-1.60)$ \\
\hline $4-9$ & & $1.75(1.34-2.29)$ \\
\hline$\geq 10$ & & $2.64(2.01-3.48)$ \\
\hline \multicolumn{3}{|l|}{ Treatment } \\
\hline Lumpectomy & 1.00 & 1.00 \\
\hline Lumpectomy + Radiation & $0.81(0.62-1.05)$ & $0.76(0.57-1.02)$ \\
\hline Mastectomy & $1.08(0.85-1.37)$ & $0.89(0.68-1.15)$ \\
\hline Mastectomy + Radiation & $1.24(0.8-1.91)$ & $1.15(0.87-1.53)$ \\
\hline
\end{tabular}

${ }^{\mathrm{a}}$ WP-working poor; WNP-UE-working, non-poor, undereducated; WNP-E-working, non-poor, educated; P-professional. 
to CA (Table 2) was 1.28 (1.15-1.44) for local, and 1.45 (1.30-1.61) for regional stage, the multivariable adjusted HR $(95 \%$ CI) of death for AA vs. CA was not significantly different for women with local stage breast cancer 1.07 (0.90-1.27), but was significantly worse for AA vs. CA among women with regional stage disease 1.27 (1.10-1.46). Older women had a greater risk of death than younger women with a HR $(95 \% \mathrm{CI})$ of 2.35 (2.0-2.77) and 1.58 (1.41-1.77) for local and regional stage disease, respectively. Also women who lived in a census block group ranked as WP or WNP-UE had a higher risk of death, compared to women who resided in a P census block group (HR $(95 \%$ CI) 1.34 (1.13-1.6) and $1.18(1.03-1.35)$ respectively for local stage disease, and $1.24(1.06-1.45)$ and $1.20(1.05-1.36)$ respectively for regional stage disease). Women diagnosed with larger tumors or those with involved axillary lymph nodes (for regional stage only) had worse survival as well. There were no significant differences in overall survival by treatment group for either local or regional stage disease.

The results of multivariable models of racial differences in breast cancer specific survival stratified by SEER registry stage are shown in Table 3. Multivariable adjustment resulted in non-significant differences in survival for AA vs. CA women with local stage disease HR (95\% CI) 1.03 (0.77-1.37). However, among women with regional stage disease, AA women continued to have significantly worse breast cancer specific survival compared to CA (HR (95\% CI) 1.40 (1.18-1.66). In these models, age was not a significant predictor of survival, and while women who resided in a census block group categorized as either WP, or WP-UE had worse survival than women living in a $\mathrm{P}$ census block group, these differences were not statistically significant. Tumor size and lymph node status were again significant predictors of survival. There were no overall significant differences by treatment for regional stage disease. However, women treated with mastectomy and radiation therapy for local stage disease had worse outcome compared to women who had lumpectomy alone (HR $2.66,95 \%$ CI $1.36-5.18)$.

\section{Discussion}

The disproportionately higher mortality rates experienced by AA women compared to CA women with breast cancer [2,31], accompanied by lower incidence rates except for women in the youngest age groups [1], is a matter of significant public health concern. The degree and extent to which differences in incidence and survival can be explained by inherent racial differences in tumor biology, and/or by factors associated with access to care,

Table 3. Hazards of the risk of breast cancer-specific death among AA and CA women with local and regional disease

\begin{tabular}{|c|c|c|}
\hline Characteristic & Local $(n=5890)$ HR $(95 \% \mathrm{CI})$ & Regional $(n=3431)$ HR $(95 \% \mathrm{CI})$ \\
\hline \multicolumn{3}{|l|}{ Unadjusted } \\
\hline Race (Black vs. White) & $1.53(1.26-1.87)$ & $1.61(1.41-1.82)$ \\
\hline \multicolumn{3}{|l|}{ Multivariable adjusted } \\
\hline Race (Black vs. White) & $1.03(0.77-1.37)$ & $1.40(1.18-1.66)$ \\
\hline \multicolumn{3}{|l|}{ Age (years) } \\
\hline$\leq 50$ & 1.00 & 1.00 \\
\hline$>50$ & $0.98(0.79-1.21)$ & $1.06(0.93-1.21)$ \\
\hline \multicolumn{3}{|l|}{ SES group ${ }^{\mathrm{a}}$} \\
\hline WP & $1.32(0.97-1.80)$ & $1.16(0.96-1.42)$ \\
\hline WNP-UE & $1.24(0.97-1.58)$ & $1.20(1.03-1.41)$ \\
\hline WNP-E & $1.00(0.78-1.31)$ & $1.04(0.87-1.24)$ \\
\hline $\mathrm{P}$ & 1.00 & 1.00 \\
\hline \multicolumn{3}{|l|}{ Tumor size } \\
\hline$\leq 2 \mathrm{~cm}$ & 1.00 & 1.00 \\
\hline $2.1-5 \mathrm{~cm}$ & $2.49(2.04-3.04)$ & $1.73(1.50-1.98)$ \\
\hline$>5 \mathrm{~cm}$ & $3.37(2.08-5.48)$ & $2.37(1.95-2.88)$ \\
\hline \multicolumn{3}{|l|}{ Lymph node involvement } \\
\hline 0 & & 1.00 \\
\hline $1-3$ & & $1.67(1.10-2.53)$ \\
\hline $4-9$ & & $2.96(1.95-4.49)$ \\
\hline$\geq 10$ & & $5.07(3.33-7.72)$ \\
\hline \multicolumn{3}{|l|}{ Treatment } \\
\hline Lumpectomy & 1.00 & 1.00 \\
\hline Lumpectomy + Radiation & $1.19(0.71-2.00)$ & $0.90(0.62-1.31)$ \\
\hline Mastectomy & $1.32(0.81-2.16)$ & $0.96(0.69-1.34)$ \\
\hline Mastectomy + Radiation & $2.66(1.36-5.18)$ & $1.38(0.97-1.98)$ \\
\hline
\end{tabular}

${ }^{\mathrm{a}}$ WP-working poor; WNP-UE-working, non-poor, undereducated; WNP-E-working, non-poor, educated; P-professional. 
is an issue that is currently being debated [31,32]. The result of this survival analysis of AA and CA women with breast cancer from the Detroit metropolitan area represents an update of an earlier analysis in which we noted an interaction between race and age, with AA women who were less than age 50 at diagnosis having worse survival experiences compared to CA women than their older counterparts.

In this report, we extended the period of follow-up from a prior maximum of 78 months [3], to 154 months, almost double the prior time period. We assessed both overall and disease specific survival, and also looked at the effect of SES on survival by incorporating a more refined measure of SES than we had used previously [3]. The current analyses show that AA women were more likely than CA women to reside in economically disadvantaged census areas, and more likely to present with more advanced breast cancer at the time of diagnosis. In addition, AA women were less likely to have had lumpectomy alone, or lumpectomy and radiation, and were more likely to have had mastectomy than CA women. Unadjusted survival analysis showed worse overall and disease specific survival for AA women, although after adjustment for common prognostic characteristics, SES, and treatment, racial differences in both overall and disease specific survival were no longer apparent for women diagnosed with local stage disease. Differences in survival by race for women with regional stage disease persisted, but were attenuated in the multivariable models.

Several previous reports have looked at the effects of SES and access to care on racial differences in breast cancer survival [3,5,7-9,11-13,15,18-22]. Using SEER data for the years 1992 through $1998, \mathrm{Li}$ et al [11] showed that AA and other ethnic minority women were less likely than CA women to receive a first course of surgical and radiation treatment that met current standards of care. In another SEER based analysis, AA women were similarly shown to be less likely to receive breast radiotherapy [8]. In two prior reports of treatment utilization using the Detroit SEER registry, we found that AA women were less likely to undergo lumpectomy and radiation therapy [33], or lumpectomy alone [22] which is consistent with our current results. In the current report AA women were more likely to need radiation following mastectomy which is likely indicative of more advanced disease. It is of interest that when assessed on a population basis, there appears to be disparity in treatment utilization, though a recent report of treatment utilization at a single NCI-designated comprehensive cancer center in Detroit revealed no racial differences in the utilization of surgery, radiation therapy, chemotherapy or hormonal therapy for breast cancer [14]. These latter results imply that when women are exposed to state-of-the-art treatment that racial differences in utilization of treatment are no longer evident.

Other investigators have shown that access to care and other sociodemographic factors account at times for a large component of the noted survival differences between AA and CA women with breast cancer. Chu et al. found racial differences in survival for younger women compared with women aged 65 and older, concluding that access to Medicare (which covered treatment costs) allowed for better survival among older women with breast cancer [9]. Adjustment for either prior mammography [15], treatment [8] or SES $[3,5,13,18,20,21]$ has accounted for a significant component of racial/ethnic differences in breast cancer survival in other studies. Because SES is known to be a significant predictor of stage at diagnosis [26], and stage at diagnosis is a strong predictor of survival, it is not surprising that we found an attenuation of racial differences after adjustment for SES. As suggested by others, our results indicate that known prognostic and predictive factors as well as SES account for at least some of the racial differences in survival seen among women with breast cancer in the Detroit metropolitan area.

The strengths of analyzing SEER registry data derive from the population-based data, the large number of cases, and the long period of follow-up. Weaknesses include missing data for some clinical variables and the fact that socioeconomic status, as derived from grouped census data, represents only a surrogate rather than an actual measure of individual socioeconomic status. On the other hand, some have argued that neighborhood SES also functions as a predictor of access to care [23]. Further research is needed to better quantify SES and to determine interventions at the community level which might have an impact on racial and SES differences in cancer mortality.

This report adds to the growing volume of data documenting racial inequity in cancer diagnosis, treatment and survival. While debate continues as to the relative degree in which biologic differences vs. access to care impact racial differences in survival, our results as well as others highlight the effect of SES on breast cancer survival. It is incumbent on the health care profession to help find solutions to inequities in access to care in our society. Mammographic screening should be accessible to all eligible women in order to eliminate the well described gap in stage at breast cancer presentation for $\mathrm{AA}$ and $\mathrm{CA}$ women.

\section{Acknowledgements}

This research was supported in part by SEER contract NIH:NCI N01-PC-35154.

\section{References}

1. Simon MS, Korczak JF, Yee CL, Daling JR, Malone KE, Bernstein L, et al:: Racial differences in the familial aggregation of breast cancer and other female cancers. Breast Cancer Res Treat 89: 227-235, 2005

2. Weir HK, Thun MJ, Hankey BF, Ries LA, Howe HL, Wingo PA, et al.: Annual report to the nation on the status of cancer, 1975- 
2000, featuring the uses of surveillance data for cancer prevention and control. J Natl Cancer Inst 95(17): 1276-1299, 2003

3. Simon MS, Severson RK: Racial differences in survival of female breast cancer in the Detroit metropolitan area. Cancer 77(2): 308314, 1996

4. Edwards MJ, Gamel JW, Vaughan WP, Wrightson WR: Infiltrating ductal carcinoma of the breast: the survival impact of race. J Clin Oncol 16(8): 2693-2699, 1998

5. O'Malley CD, Le GM, Glaser SL, Shema SJ, West DW: Socioeconomic status and breast carcinoma survival in four racial/ethnic groups: a population-based study. Cancer 97(5): 1303-1311, 2003

6. Clegg LX, Li FP, Hankey BF, Chu K, Edwards BK: Cancer survival among US whites and minorities: a SEER (Surveillance, Epidemiology, and End Results) Program population-based study. Arch Intern Med 162(17): 1985-1993, 2002

7. Shavers VL, Harlan LC, Stevens JL: Racial/ethnic variation in clinical presentation, treatment, and survival among breast cancer patients under age 35. Cancer 97(1): 134-147, 2003

8. Joslyn SA: Racial differences in treatment and survival from earlystage breast carcinoma. Cancer 95(8): 1759-1766, 2002

9. Chu KC, Lamar CA, Freeman HP: Racial disparities in breast carcinoma survival rates: seperating factors that affect diagnosis from factors that affect treatment. Cancer 97(11): 2853-2860, 2003

10. Joslyn SA: Hormone receptors in breast cancer: racial differences in distribution and survival. Breast Cancer Res Treat 73(1): 45-59, 2002

11. Li CI, Malone KE, Daling JR: Differences in breast cancer stage, treatment, and survival by race and ethnicity. Arch Intern Med 163(1): 49-56, 2003

12. Grann V, Troxel AB, Zojwalla N, Hershman D, Glied SA, Jacobson JS: Regional and racial disparities in breast cancer-specific mortality. Soc Sci Med: Epud ahead of print, 2005

13. Delgado DJ, Lin WY, Coffey M: The role of Hispanic race/ethnicity and poverty in breast cancer survival. P R Health Sci J 14(2): 103-116, 1995

14. Du W, Simon MS: Racial disparities in treatment and survival of women with stage I-III breast cancer at a large academic medical center in Metropolitan Detroit. Breast Cancer Res Treat, 2005

15. Wojcik BE, Spinks MK, Stein CR: Effects of screening mammography on the comparative survival rates of African American, white, and Hispanic beneficiaries of a comprehensive health care system. Breast J 9(3): 175-183, 2003

16. Jatoi I, Becher H, Leake CR: Widening disparity in survival between white and African-American patients with breast carcinoma treated in the US Department of Defense Healthcare system. Cancer 98(5): 894-899, 2003

17. Mancino AT, Rubio IT, Henry-Tillman R, Smith LF, Landes $\mathrm{R}$, Spencer HJ, et al.: Racial differences in breast cancer survival: the effect of residual disease. J Surg Res 100(2): 161-165, 2001

18. Yood MU, Johnson CC, Blount A, Abrams J, Wolman E, McCarthy BD, et al.: Race and differences in breast cancer survival in a managed care population. J Natl Cancer Inst 91(17): 1487-1491, 1999
19. Ansell D, Whitman S, Lipton R, Cooper R: Race, income, and survival from breast cancer at two public hospitals. Cancer 72(10): 2974-2978, 1993

20. Bradley CJ, Given CW, Roberts C: Race socioeconomic status, and breast cancer treatment and survival. J Natl Cancer Inst 94(7): 490-496, 2002

21. Gordon NH, Crowe JP, Brumberg DJ, Berger NA: Socioeconomic factors and race in breast cancer recurrence and survival. Am $\mathbf{J}$ Epidemiol 135(6): 609-618, 1992

22. Simon MS, Severson RK: Racial differences in breast cancer survival: the interaction of socioeconomic status and tumor biology. Am J Obstet Gynecol 176(6): S233-S239, 1997

23. Diez-Roux AV, Kiefe CI, Jacobs DR, Jr., Haan M, Jackson SA, Nieto FJ, et al : Area characteristics and individual-level socioeconomic position indicators in three population-based epidemiologic studies. Ann Epidemiol 11(6): 395-405, 2001

24. International classification of diseases for oncology. 2nd ed. World Health Organization, Geneva, 1990

25. Henson DE, Ries L, Shambaugh EM: Survival results depend on the staging system. Semin Surg Oncol 8(2): 57-61, 1992

26. Schwartz KL, Crossley-May H, Vigneau FD, Brown K, Banerjee $\mathrm{M}$ : Race, socioeconomic status and stage at diagnosis for five common malignancies. Cancer Causes Control 14(8): 761-766, 2003

27. US Census Bureau. Census of Population and Housing Summary Tape File 3 Technical Documentation. 1991. US Census Bureau, Washington DC, 1990

28. Krieger N, Quesenberry C, Jr., Peng T, Horn-Ross P, Stewart S, Brown S, et al : Social class, race/ethnicity, and incidence of breast, cervix, colon, lung, and prostate cancer among Asian, Black, Hispanic, and White residents of the San Francisco Bay Area, 1988-92 (United States). Cancer Causes Control 10(6): 525537, 1999

29. Neter J, Wasserman W, Kutner M: Applied linear statistical models: regression, analysis of variance and experimental design. 2nd ed. Richard D. Irwin, Inc, Homewood, IL, 1985

30. Cox DR, Oakes DO: Analysis of survival data. Chapman and Hall, London, 1984

31. Newman LA, Mason J, Cote D, Vin Y, Carolin K, Bouwman D, et al : African-American ethnicity, socioeconomic status, and breast cancer survival: a meta-analysis of 14 studies involving over 10,000 African-American and 40,000 White American patients with carcinoma of the breast. Cancer 94(11): 2844-2854, 2002

32. Shavers VL, Brown ML: Racial and ethnic disparities in the receipt of cancer treatment. J Natl Cancer Inst 94(5): 334-357, 2002

33. Chuba PJ, Simon MS: Trends in primary surgical and radiation therapy for localized breast cancer in the Detroit Metropolitan area 1973-1992. Int J Radiat Oncol Biol Phys 38(1): 103-107, 1997

Address for offprints and correspondence: Michael S. Simon, Barbara Ann Karmanos Cancer Institute, 4100 John R, 4221 HWCRC Detroit, MI, USA; Tel.: +1-313-576-8727; Fax: +1-313-576-8764; E-mail: Simonm@karmanos.org 